\title{
25 Research Square \\ Effect Analysis of a Virtual Simulation Experimental Platform in Teaching Pulpotomy
}

\section{Jiaxuan Lu}

Sun Yat-sen University

\section{Xin Yang}

Sun Yat-sen University

Wei Zhao

Sun Yat-sen University

Jiacheng Lin ( $\nabla$ linjiach@mail.sysu.edu.cn )

Sun Yat-sen University https://orcid.org/0000-0002-8994-4635

\section{Research article}

Keywords: svirtual simulation experimental teaching, virtual simulation experimental teaching platform, experimental teaching, pulpotomy, pediatric dentistry

Posted Date: July 2nd, 2021

DOI: https://doi.org/10.21203/rs.3.rs-668236/v1

License: (c) (1) This work is licensed under a Creative Commons Attribution 4.0 International License. Read Full License 


\section{Abstract}

Background: The experimental teaching of pediatric dentistry is a bridge between theoretical study and clinical practice, and virtual simulation technology provides a new way of instruction.

Methods: We have built an experimental teaching platform using virtual simulation technology for vital pulpotomy that includes learning and examination modes. There were 199 students who were majoring in stomatology in the fourth year in Sun Yat-Sen University randomly divided into a control group (conventional teaching mode) and an experimental group (virtual simulation experimental teaching model). The teaching effect was evaluated by theoretical and experimental examination.

Results: We found that the theoretical and experimental scores of the experimental group were both higher than those of the control group, and the theoretical scores of the experimental group after exposure to the virtual simulation experimental teaching platform were also higher than those before the class. The differences were statistically significant $(P<0.05)$. Feedback from the experimental group after the class indicated that the platform reinforced their theoretical knowledge and greatly improved their mastery of operational skills.

Conclusions: The application of a virtual simulation experimental teaching platform can effectively improve teaching pulpotomy.

\section{Background}

With the popularization and development of modern educational technology, virtual simulation experimental teaching has become a new method of instruction. Characteristic of virtual simulation experiment teaching is that the operator can enter interact with a three-dimensional virtual reality environment generated by the computer [1-3]. Through the interaction between participants and the virtual simulation environment, and with the help of people's own perceptions and cognitive abilities, various spatial and logical information contained in the virtual environment can be understood in a comprehensive way.

Virtual simulation experimental teaching is one of the reforms in higher education and is an important part of an experimental teaching demonstration center, the product of the integrating the discipline and information technology [4-6]. It focuses on the construction of networked experimental teaching resources to continuously promote the development of experimental teaching in colleges and universities [4-7].

In 2013, the Ministry of Education of the People's Republic of China constructed a national virtual simulation experimental teaching center [8]. Virtual simulation technology is now being applied more often in the field of stomatology. The clinical science of stomatology is a discipline that emphasizes strong practical ability and good comprehension. Wang et al. [9] used the Simodont virtual simulation system in cariology experimental teaching, finding that it helps to improve students' operational skills. 
Wang et al. [10] used the virtual technique in fixed denture teaching to effectively convey the abstract three-dimensional concept to dental students and enhance students' three-dimensional perception of dental repair. Zhong et al. [11] combined the oral virtual simulation experimental teaching platform with a digital section on oral histopathology and found that virtual simulation experimental teaching could effectively stimulate students' interest in learning, thus improving the teaching results.

However, there has not been any report about the application of a virtual simulation experimental platform in teaching pediatric stomatology. Pediatric dentistry is an important part of clinical science of stomatology, and it covers a full range of oral diagnosis and treatment and preventive measures for children of a certain age [12-14]. The teaching of pediatric dentistry consists of three curriculum stages: theoretical study, experimental teaching, and clinical practice training.

Experimental teaching is the link between theoretical teaching and clinical practice. The existing experimental teaching of pediatric dentistry in China mainly covers dental caries fillings, pulp resection, root canal therapy, etc. However, because of the constraints of costs, laboratory management, and human and material resources, students cannot practice repeatedly and master the experimental contents immediately, and it is naturally impossible for them to acquire the corresponding technical knowledge before entering the clinic. In particular, a model of young permanent teeth with open apices is still laching for projects such as young permanent tooth pulpotomy, apexification, and pulp regeneration therapy, so students cannot perform relevant exercises in class.

Endodontic treatment is an important part in teaching pediatric dentistry. Pulpotomy is a minimally invasive endodontic treatment concept vigorously advocated in recent years, which effectively makes up for the limitations of traditional endodontic treatment and has received much attention [15-17]. However, this technique is very demanding to carry out, and the failure rate among students is high. Once this technique fails, the affected teeth have irreversible damage.

In order to solve the difficulties in experimental teaching, our hospital (Guanghua School of Stomatology, Hospital of Stomatology, Sun Yat-sen University)

selected pulpotomy, a common treatment in pediatric dentistry, and developed a virtual simulation experimental project in September 2018. Based on the existing virtual simulation experimental platform of the Ministry of Education of the People's Republic of China, we independently developed a virtual simulation experimental platform for teaching pulpotomy so that students could master the examination, diagnosis, treatment plan, and the specific operative steps of pulpotomy (www.ilab-x.com/details? id=2852\&isView=true). This project has been supported by the National Virtual Simulation Experiment Construction Project of Stomatology in China, which is also the only virtual simulation experimental project in pediatric dentistry in China.

We investigated whether the application of a virtual simulation experimental platform for teaching pulpotomy can effectively improve the teaching quality in our school (Guanghua School of Stomatology, Sun Yat-sen University). 


\section{The Characteristics of a Virtual Simulation Experimental Platform for Teaching Pulpotomy}

This experimental platform is supported by Beijing Rainier Network Technology Co., Ltd. (Beijing, China; www.rainier.et.cn). The platform is based on computer simulation, multimedia, and network technologies and uses a service-oriented B/S architecture design, including two modes of learning and examination (www.ilab-x.com/details?id=2852\&isView=true).

The design of the virtual environment, including the layout of the clinic and the materials and equipment for clinical application, were base on the environment in our hospital.

The experiment simulated the whole process of clinical reception, examination, diagnosis, and clinical treatment of young permanent teeth after trauma and deciduous teeth with reversible pulpitis.

The clinical procedures were done in accordance with the pulpotomy procedures in McDonald and Avery's Dentistry for the Child and Adolescent 9th Edition, 2010 [18].

In the learning mode, users can complete the whole process of simulated case reception, examination, diagnosis, and pulpotomy of primary teeth and young permanent teeth step-by-step in a simulated clinical environment according to the prompts.

In the examination mode, the contents and standards of objective evaluation are presented as multiplechoice questions according to the key points that need to be mastered in clinical practice. Ten key points of clinical technology, such as indication selection and aseptic operation, are covered and corresponding scores are given. At the same time, the examination mode can be repeated and human-computer interactions analyzed retrospectively.

At the same time, teachers can use the interactive aspect of network learning to track and understand students' learning time, progress, and mastery of the material to promote students' learning and improve teaching effectiveness. Moreover, in order to better assist students in learning, the platform also includes a film of the complete process for standard pulpotomy for students' reference.

The platform is jointly maintained by the Department of Children's Stomatology and the Laboratory Management Center of Guanghua School of Stomatology, Sun Yat-sen University and the Department of Pediatric Dentistry in our hospital and Guangdong Provincial Key Laboratory of Stomatology and is available 24 hours a day. Not only students in Sun Yat-sen University but also users outside the university can visit and study. Users can access the platform for an unlimited amount of time.

\section{Methods}

\section{The research objective}


There were 199 students who major in stomatology in the fourth year in Guanghua School of Stomatology, Sun Yat-Sen University during May 2019 to December 2020 who were randomly divided into a control group (conventional teaching mode) and experimental group (virtual simulation experimental teaching model). There were 101 students in the experimental group and 98 in the control group.

\section{The research process}

Two examination questions (paper 1 and paper 2) were designed, including disease diagnosis and prognosis judgment (dimension 1), operative points of pulpotomy (dimension 2), and related knowledge expansion (dimension 3). There were 10 items in total in three dimensions. A questionnaire for a virtual simulation experiment was also designed.

The instructor taught the students the theory of pulpotomy, using McDonald and Avery's Dentistry for the Child and Adolescent 9th Edition, 2010 [18].

At the end of the course, both the experimental group and the control group completed the test paper A, which was submitted and recorded as the grade A score.

Students in the experimental group were instructed to log in the experimental system to watch the video of pulpotomy, enter the "practice mode" of the virtual experimental platform, and learn and practice the virtual simulation experimental course. The virtual simulation experiment was not performed in the control group.

According to the Ebbinghaus Forgetting Curve [19], two groups of students to completed test paper B a week later and identified it as the grade B score. Then, they entered the "test mode" of the virtual experimental platform to complete the experimental assessment. The score data of the two groups of students in the "test mode" of the virtual experimental platform were designated as grade $\mathrm{C}$ scores. After the assessment, the experimental group completed the questionnaire. All the examination questions and questionnaires were completed in the class, with an effective recovery rate of $100 \%$.

\section{Statistical analysis}

The grade A, B, and C scores of the two groups of students were input into SPSS 20.0 software (SPSS Inc., Chicago, Illinois, USA). The data are shown as means \pm standard deviations. Statistical analyses were performed using one-way analysis of variance, and the $t$-test was used for multiple comparisons. $P$ $<0.05$ was considered statistically significant.

\section{Results}

\section{Comparison of the grades between the two groups}

The average grade A score of the experimental group was slightly lower than that of the control group, but there was no statistically significant difference between them (Table 1), which ensures that the two 
groups of students were at the same baseline before the experiment.

Table 1

Comparison of the grade A scores

\begin{tabular}{|lllll|}
\hline Grade A & $\begin{array}{l}\text { Experimental } \\
\text { Group }(\mathbf{n = 1 0 1 )}\end{array}$ & Control Group $(\mathbf{n = 9 8 )}$ & $\boldsymbol{t}$ & $\boldsymbol{P}$-value \\
\hline Total points & $7.28 \pm 1.49$ & $7.84 \pm 1.37$ & -1.383 & 0.173 \\
\hline Dimension 1 & $3.32 \pm 0.75$ & $3.36 \pm 0.70$ & -0.195 & 0.846 \\
\hline Dimension 2 & $2.32 \pm 0.80$ & $2.80 \pm 1.00$ & -1.872 & 0.067 \\
\hline Dimension 3 & $1.56 \pm 0.51$ & $1.68 \pm 0.56$ & -0.797 & 0.429 \\
\hline$* p<0.05, * * p<0.01$ & & & \\
\hline
\end{tabular}

After the training on the virtual simulation experimental teaching platform in pulpotomy teaching, the grades $\mathrm{B}$ and $\mathrm{C}$ scores in the experimental group were significantly higher than that of the control group (Tables 2 and 3), mainly on the operative points of pulpotomy (dimension 2). This suggests that the virtual simulation experimental course can increase students' technical proficiency and the memory of the operative points to help make teaching more effective.

Table 2

Comparison of grade B scores

\begin{tabular}{|c|c|c|c|c|c|}
\hline Grade B & Experimental & \multicolumn{2}{|c|}{ Control Group $(n=98)$} & $t$ & $P$-value \\
\hline Total points & $8.16 \pm 1.11$ & $7.60 \pm 0.87$ & 1.993 & & 0.032 * \\
\hline Dimension 1 & $3.28 \pm 0.54$ & $3.44 \pm 0.51$ & -1.079 & & 0.286 \\
\hline Dimension 2 & $3.44 \pm 0.58$ & $2.56 \pm 0.65$ & 5.036 & & $0.000 * *$ \\
\hline Dimension 3 & $1.44 \pm 0.51$ & $1.64 \pm 0.57$ & -1.313 & & 0.195 \\
\hline
\end{tabular}

Table 3

Comparison of grade $\mathrm{C}$ scores

\begin{tabular}{|c|c|c|c|c|}
\hline & & $\nabla X \pm S$ & $t$ & $P$-value \\
\hline \multirow[t]{3}{*}{ Grade C } & Experimental & $85.0 \pm 8.29$ & \multirow[t]{3}{*}{1.142} & \multirow[t]{3}{*}{0.035 * } \\
\hline & \multicolumn{2}{|l|}{ Group $(n=101)$} & & \\
\hline & Control Group $(n=98)$ & $82.2 \pm 9.02$ & & \\
\hline
\end{tabular}


As shown in Table 4, the difference between grade A and grade B scores in the experimental group was statistically significant, indicating that scores after training were higher than before training. However, there was no statistically significant difference between A and B scores in the control group (Table 5). This indicates that the virtual simulation platform in pulpotomy teaching was effective in improving students' scores.

Table 4

Comparison of grade $A$ and grade $B$ scores in the experimental group

\begin{tabular}{|lllll|}
\hline Variable & Grade A & Grade B & $t$ & $P$-value \\
\hline Total points & $7.33 \pm 1.40$ & $8.20 \pm 1.03$ & -4.419 & 0.000 ** \\
\hline Dmension 1 & $3.30 \pm 0.75$ & $3.27 \pm 0.52$ & 0.273 & 0.787 \\
\hline Dimension 2 & $2.37 \pm 0.76$ & $3.43 \pm 0.57$ & -9.133 & 0.000 ** \\
\hline Dimension 3 & $1.60 \pm 0.50$ & $1.50 \pm 0.51$ & 0.902 & 0.375 \\
\hline$* p<0.05, * * p<0.01$ & & & \\
\hline
\end{tabular}

Table 5

Comparison of grade A and grade B scores in the control group

\begin{tabular}{|c|c|c|c|c|}
\hline Variable & Grade A & Grade B & $t$ & $P$-value \\
\hline Total points & $7.83 \pm 1.26$ & $7.67 \pm 0.84$ & 0.926 & 0.362 \\
\hline Dmension 1 & $3.33 \pm 0.66$ & $3.43 \pm 0.50$ & -0.648 & 0.522 \\
\hline Dimension 2 & $2.80 \pm 0.96$ & $2.57 \pm 0.63$ & 1.424 & 0.165 \\
\hline Dimension 3 & $1.70 \pm 0.53$ & $1.70 \pm 0.53$ & 0.000 & 1.000 \\
\hline \multicolumn{5}{|c|}{$\star p<0.05, * * p<0.01$} \\
\hline
\end{tabular}

\section{Feedback from the questionnaire in the experimental group}

From the feedback for the questionnaire (Fig. 3), all students thought that the virtual simulation experimental teaching platform is very helpful for learning. Through the platform, it was easier to get familiar with the process of pulpotomy and master the difficulties and key points of the technology. More than $90 \%$ of the students liked this teaching method and had more enthusiasm for learning in the simulation condition.

Students also offered some opinions on the virtual simulation experimental teaching platform for pulp amputation. They hoped that more experiments using vitro teeth or dental models could be added to the virtual simulation experiment and the experimental steps made more meticulous, virtual simulation effect more vivid, and the platform made more interactive. 


\section{Discussion}

\section{The establishment of a virtual simulation teaching experomental platform is innovative}

In China, patients are increasingly knowledgeable about procedures, and the medical conflict between doctors and patients is becoming increasingly prominent. Most children receiving oral treatment are unlikely to cooperate with the dentist, and parents often hope that their children can be treated by a skilled dentist. This requires

students to master the operative technology before entering the clinic to establish a good foundation for future clinical work. The traditional teaching model, which mainly focuses on theory, cannot meet practical training requirements for dental students.

Pulp defense and self-repair is the biological basis of pulp repair and live pulp preservation [20, 21] Pulpotomy is a method of removing the crown pulp tissue under local anesthesia and covering the pulp wound with viable pulp to preserve the normal pulp tissue at the root [18]. It is difficult to carry out pulpotomy in experimental teaching, because the pulp condition of young permanent teeth cannot be simulated in the laboratory.

Using virtual simulation technology, however, the abstract concepts and independent technical operations of the textbook can be transformed into intuitive and controllable simulation graphics and images, and teaching can be simplified [22-24]. Virtual simulation experimental teaching can solve many problems encountered in conventional offline teaching and become an important supplement to conventional teaching.

This study introduced virtual simulation technology. It can provide students with cases that simulate a doctor-patient environment, as well as repeatable virtual simulations of pulpotomy, by simulating the operation of pediatric dentistry departments and providing an interactive link for learning through virtual simulation teaching experiments.

The experimental survey shows that students using the virtual simulation experimental platform can learn repeatedly regardless of time and space constraints to become more familiar with the operative process and main technical points of pulpotomy. The platform can accurately illustrate the process of clinical diagnosis and treatment, and students can develop their skills in a noninvasive, risk-free, and repeatable way.

The virtual simulation teaching experimental platform enhances teaching effectiveness and promotes the reform of experimental teaching

Previous studies have shown that virtual simulation teaching plays an auxiliary role in medical teaching, assessment, and autonomous learning [25-29]. The results of this study showed that after virtual 
simulation experimental training, the theoretical performance was better than in the control group, and the use of the virtual simulation experimental system improved learning performance and teaching effectiveness, indicating that the teaching design is effective and should continue to be used and promoted.

In addition, the statistical differences in the theoretical examination mainly reflected differences in the pulp amputation operation dimension, and the operation examination scores were higher for the experimental group than for the control group. This indicates that the virtual simulation teaching platform is effective in improving practical skills in teaching pulpotomy. This teaching platform, which is always available, includes detailed text explanations, so that obscure language and words are presented to students through intuitive and easy to understand pictures. Compared with the self-study forms after class in the control group, students in the experimental group could preview lessons before class and review them after class on the platform at any time, which can improve the utilization of teaching resources and resource sharing. The platform has the advantages that the conventional teaching mode does not have. It can help students to develop their own thinking, promote the improvement of independent learning ability and practical ability, strengthen the mastery of relevant knowledge and skills, and encourage students to carry out active exploratory learning.

The virtual simulation teaching experimental system can record students' personal learning trajectory. In this experiment, using the actual data on the platform, teachers can monitor the progress of students in completing the exercises. This provides important first-hand information for teachers to know the status of students and is an important basis for obtaining formative evaluation of the course. This project includes three parts: pre-class multimedia learning, virtual practice, and examination. The platform not only evaluates students' mastery and proficiency of the technology through an interactive process but also has strict assessment and scoring standards. During and after the training, human-computer interaction can be retroactively analyzed according to the learning dynamic trajectory recorded by the platform to provide reference data for targeted optimization of teaching efficiency. Compared with the traditional examination method, virtual simulation teaching is more timely and can measure training and assessment and make continuous improvements according to the feedback [30,31]. Through the open platform, students can receive timely feedback from the instructor that helps learning and consolidation and interact with teachers online, which also significantly improves students' learning initiative, enthusiasm, and efficiency. This is conducive to cultivating students' independent learning.

Through the feedback on the questionnaire, all the students thought that the virtual simulation experiment platform was helpful for learning, and more than $90 \%$ of the students liked this learning method. Students also hoped that more educational content could be added to the virtual simulation teaching experimental platform. Through the combination of information technology and experimental teaching, the virtual simulation teaching experimental platform has developed an innovative teaching mode of "virtual simulation training and simulated head model experimental teaching." 
In the future, we will continue to update and maintain the pulpotomy virtual simulation experimental teaching platform and promote the platform so that more dental students and dentists can benefit from it.

\section{Conclusions}

The combination of virtual simulation experimental teaching and real experiment can complement each other's advantages, which can really improve the effect of experimental teaching and is conducive to the sharing and optimization of educational resources. At the same time, it can also mobilize students' enthusiasm and initiative for participating in experimental teaching. Applying information technology to experimental teaching, establishing an open and networked virtual simulation experimental teaching system, and establishing an training model can effectively make up for the deficiency of traditional experimental teaching.

\section{Declarations}

\section{Acknowledgements}

We would like to thank all applicants who participated in this study.

\section{Authors' contributions}

Jiaxuan Lu and JiaCheng Lin planned the study and constructed the questionnaires. Jiaxuan Lu and Xin Yang analyzed evaluation date and contributed to writing the manuscript. All authors read and approved the final manuscript.

\section{Funding}

This work was supported by grants from the Sun Yat-sen University Clinical Research 5010 Program (2019015) to J. C. Lin and the National Virtual Simulation Experiment Construction Project in China (2018-2-0259) .

\section{Availability of data and materials}

All data and materials are available from the corresponding author upon request.

\section{Ethics approval and consent to participate}

Ethical approval was granted by the School of Stomatology, Sun Yat-sen University.

\section{Consent for publication}

Not applicable. 


\section{Conflicting Interest}

There are no competing financial interests among the authors.

\section{References}

[1] Xu X, Allen W, Miao Z, Yao J, Sha L, Chen Y. Exploration of an interactive "Virtual and Actual Combined" teaching mode in medical developmental biology. Biochem Mol Biol Educ, 2018,46(6):585-591.

[2] Yuan YB, Wang JJ, Lin MH, Gao XY. Building virtual simulation teaching platform based on electronic standardized patient. Sheng Li Xue Bao, 2020,72(6):730-736.

[3] Wang Q, Li C, Xie Z, Bu Z, Shi L, Wang C, Jiang F. The Development and Application of Virtual Reality Animation Simulation Technology: Take Gastroscopy Simulation System as an Example. Pathol Oncol Res, 2020,26(2):765-769.

[4] Quiroga M, Choate JK. A virtual experiment improved students' understanding of physiological experimental processes ahead of a live inquiry-based practical class. Adv Physiol Educ, 2019,43(4):495503.

[5] Rifaioglu AS, Atas H, Martin MJ, Atalay RC, Atalay V, Dogan T. Recent applications of deep learning and machine intelligence on in silico drug discovery: methods, tools and databases. Brief Bioinform, 2019,20(5):1878-1912.

[6] Pasquier P, Gaudry S, Tesniere A, Mignon A. New insights into virtual medical education and assessment, Serious Games, and Digital Platforms. Bull Acad Natl Med, 2015,199(7):1153-1164.

[7] Ray S, Koshy NR, Reddy PJ, Srivastava S. Virtual Labs in proteomics: new E-learning tools. J Proteomics, 2012,75(9):2515-2525.

[8] Li P, Mao C, Xu J. Construction of the National Vitural Simulation Experiment Teaching Centers, improving the experimental teaching informatization in higer education. Research and Exploration in Laboratory, 2013,32(11):5-8.

[9] Wang G, Zhang J, Zhang W. Application of Simodont system in cariology experiment teaching. China Medical Education Technology, 2017,31(01):33-37.

[10] Wang F, Tan W, Niu L. Study of virtual technique in fixed denture teaching parctice. Northwest Medical Education, 2018,26(05):881-883.

[11] Zhong Q, Zhen Y, Song X, Liu L, Zhang W. Application and evaluation of oral histopathology digital slice based on oral virtual simulation experimental teaching platform. China Higher Medical Education, 2019(06):3-4. 
[12] Chi DL. The Science and Art of Evidence-Based Pediatric Dentistry. Dent Clin North Am, 2017,61(3):xixii.

[13] Miller J. American Academy of Pediatric Dentistry-The BIG Authority On Little Teeth: A Future Brighter Then Eve. Pediatr Dent, 2016,38(3):186.

[14] Gelbier S, Kupietzky A, Tsai AT. History of the International Association of Paediatric Dentistry: A 50year perspective. Int J Paediatr Dent, 2019,29(3):387-402.

[15] Stringhini JE, Vitcel ME, Oliveira LB. Evidence of pulpotomy in primary teeth comparing MTA, calcium hydroxide, ferric sulphate, and electrosurgery with formocresol. Eur Arch Paediatr Dent, 2015,16(4):303312.

[16] Yang Y, Xia B, Xu Z, Dou G, Lei Y, Yong W. The effect of partial pulpotomy with iRoot BP Plus in traumatized immature permanent teeth: A randomized prospective controlled trial. Dent Traumatol, 2020,36(5):518-525.

[17] Ozgur B, Uysal S, Gungor HC. Partial Pulpotomy in Immature Permanent Molars After Carious Exposures Using Different Hemorrhage Control and Capping Materials. Pediatr Dent, 2017,39(5):364-370.

[18] Jeffrey A. Dean (2010). McDonald and Avervy's Dentistry for the Child and Adolescent 9th Edition. (America, Elsevier)

[19] Murre JM, Dros J. Replication and Analysis of Ebbinghaus' Forgetting Curve. PLoS One, 2015,10(7):e120644.

[20] Ricucci D, Loghin S, Niu LN, Tay FR. Changes in the radicular pulp-dentine complex in healthy intact teeth and in response to deep caries or restorations: A histological and histobacteriological study. J Dent, 2018,73:76-90.

[21] Andreasen FM, Kahler B. Pulpal response after acute dental injury in the permanent dentition: clinical implications-a review. J Endod, 2015,41(3):299-308.

[22] Zhang B, Li S, Gao S, Hou M et al. Virtual versus jaw simulation in Oral implant education: a randomized controlled trial. BMC Med Educ, 2020,20(1):272.

[23] Kin T, Nakatomi H, Shono N, Nomura S, Saito T, Oyama H, Satio N. Neurosurgical Virtual Reality Simulation for Brain Tumor Using High-definition Computer Graphics: A Review of the Literature. Neurol Med Chir (Tokyo), 2017,57(10):513-520.

[24] Perry S, Bridges SM, Burrow MF. A review of the use of simulation in dental education. Simul Healthc, 2015,10(1):31-37. 
[25] Wang D, Zhao S, Li T, Zhang Y, Wang X. Preliminary evaluation of a virtual reality dental simulation system on drilling operation. Biomed Mater Eng, 2015,26 Suppl 1:S747-S756.

[26] Zhang X, Yang J, Chen N, Zhang S, Xu Y, Tan L. Modeling and simulation of an anatomy teaching system. Vis Comput Ind Biomed Art, 2019,2(1):8.

[27] Pezel T, Coisne A, Bonnet G, Marins RP, et al. Simulation-based training in cardiology: State-of-the-art review from the French Commission of Simulation Teaching (Commission d'enseignement par simulation-COMSI) of the French Society of Cardiology. Arch Cardiovasc Dis, 2021,114(1):73-84.

[28] Zhou X, Zhang L, Ye L, Xiang T, Wang Y. Application of virtual simulation technology in field of dental education. Experimental Technology and Management, 2014,31(05):4-6.

[29] Tsai SL, Chai SK, Hsieh LF, Lin S, Taur FM, Sung WH, Dong JL The use of virtual reality computer simulation in learning Port-A cath injection. Adv Health Sci Educ Theory Pract, 2008,13(1):71-87.

[30] Soltanimehr E, Bahrampour E, Imani MM, Rahimi F, Almasi B, Moattari M. Effect of virtual versus traditional education on theoretical knowledge and reporting skills of dental students in radiographic interpretation of bony lesions of the jaw. BMC Med Educ, 2019,19(1):233.

[31] Hou Y, Shi J, Lin Y, Chen H, Yuan W. Virtual surgery simulation versus traditional approaches in training of residents in cervical pedicle screw placement. Arch Orthop Trauma Surg, 2018,138(6):777-782.

\section{Figures}
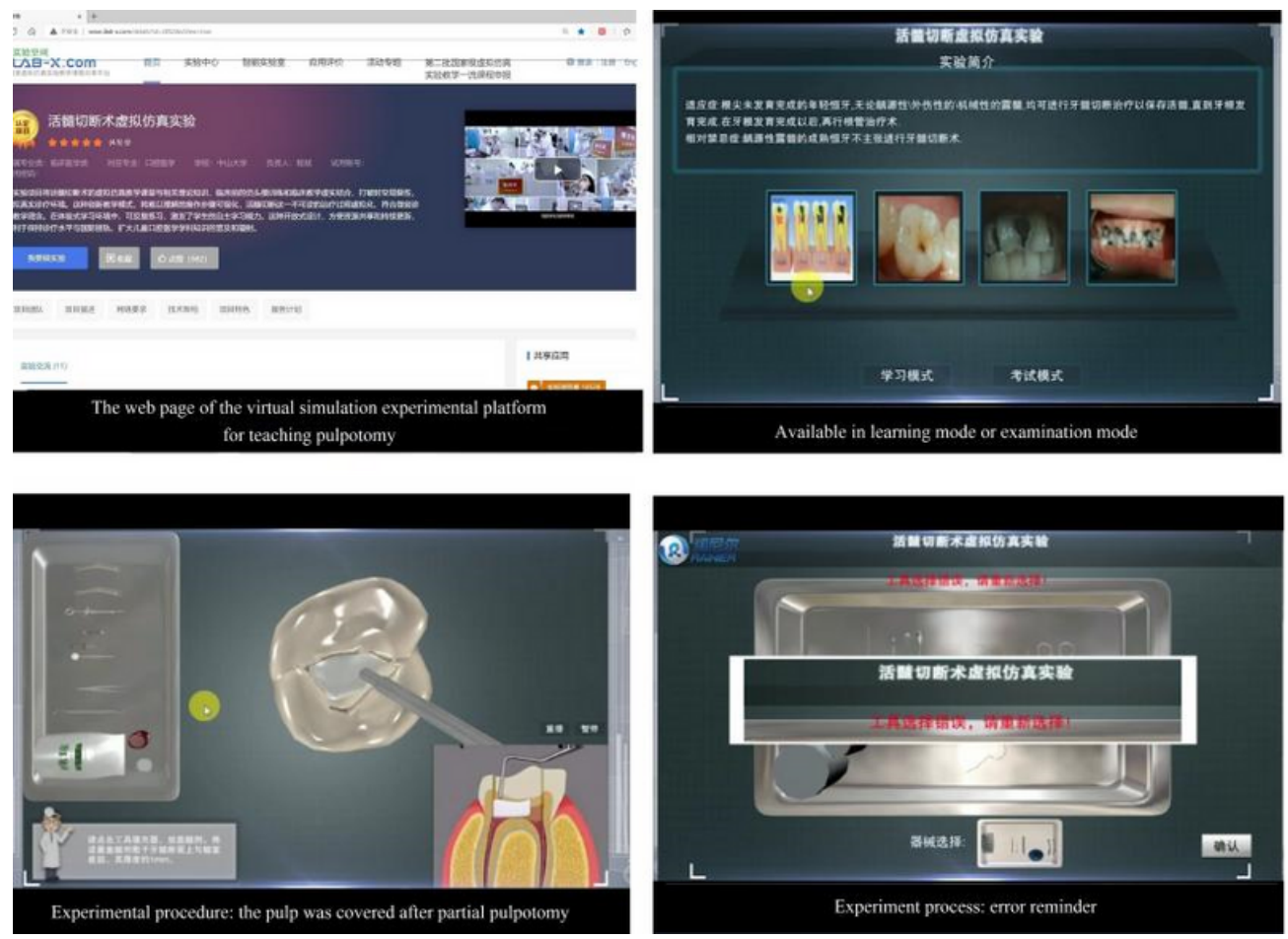
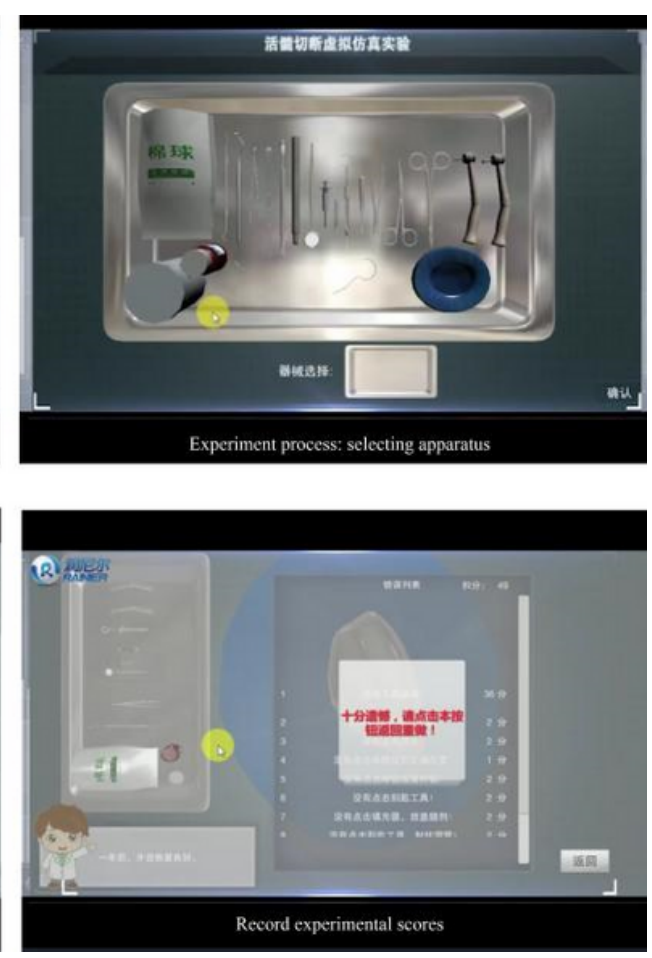

\section{Figure 1}


The Virtual Simulation Experimental Platform for Teaching Pulpotomy

Two examination questions (paper 1 and paper 2)
were designed

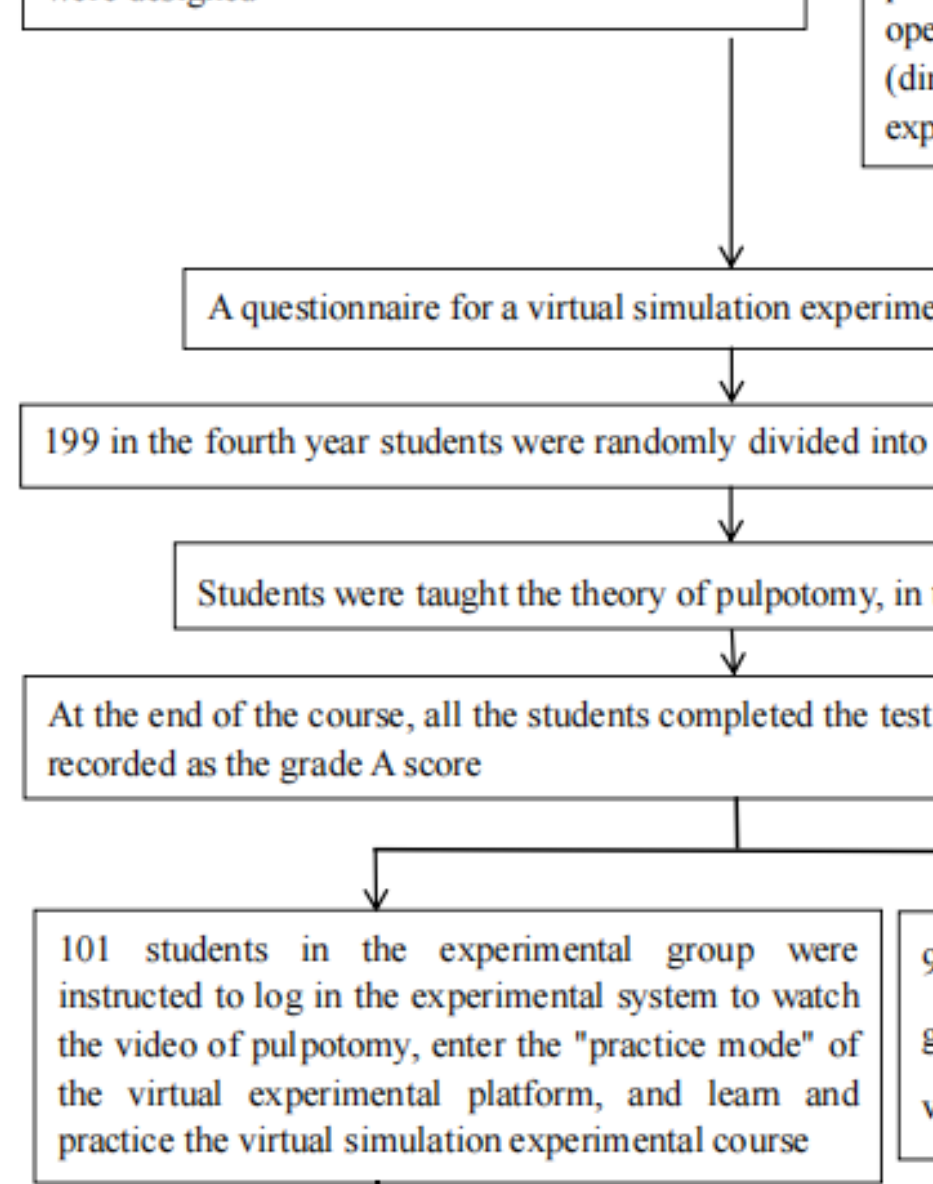

10 items including disease diagnosis and prognosis judgment (dimension 1), operative points of pulpotomy (dimension 2), and related knowledge expansion (dimension 3)

$$
\text { one week later }
$$

Two groups of students to completed test paper B and identified it as the grade

B score

All the students entered the "text mode" of the virtual experimental platform to
complete the experimental assessment, as grade C scores

$\downarrow$ After the assessment

\section{Figure 2}

Design of the research study 
I have a better understanding of the technical points and difficulties of pulpotomy

It's easier for me to get familiar with the process of endodontistry

I have a strong enthusiasm for pulp amputation

The virtual simulation experiment teaching platform is very convenient to operate

I like the virtual simulation experiment very much

Virtual simulations experiments are inconvenient and a waste of time

$\begin{array}{llllll}0 & 20 & 40 & 60 & 80 & 100\end{array}$

Strong agree

\section{Figure 3}

\section{Questionnaire Results}

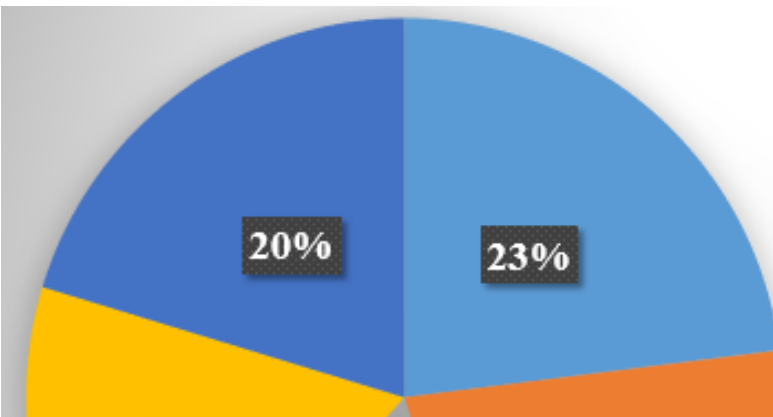

$73,18 \%$

$17 \%$
Add more experimental content

More detailed and vivid experiments

The platform provides more information about new entrants

The experimental process is simple and convenient

More interactive communication modes

\section{Figure 4}

Outlook and Comments 